deal between large purchasers and powerful providers. Furthermore, many of the larger purchasing authorities have inherited a higher uptake of these services than the more peripheral purchasers, to the financial disadvantage of the peripheral purchasers if the cash devolved by the regional health authority to the districts has been determined mainly by past patterns of uptake.

Regional services are not exclusively high in cost and low in volume. Similar problems may be facing other services. Recent publicity has focused on a highly specialised soft tissue tumour pathology service which has until now been funded by a charity, which rightly believes that the service should now be the NHS's responsibility. This reference service receives about 1100 specimens a year, of which 800 are from several hundred different British hospitals. Its total running cost is over $£ 160000$ a year. Not being a clinical service, it is ineligible for support from the Supra Regional Services Advisory Group.

The Department of Health has, however, just issued guidance on the operation, from 1 April, of notification arrangements for tertiary extracontractual referrals. ${ }^{5}$ The guidelines cover referrals of pathological specimens for a second opinion or extra tests where such referrals amount to a significant part of the receiving unit's workload. In such situations the receiving unit will have, firstly, to ensure that the referring unit is aware that a charge will apply and, secondly, arrange for invoicing and collection of payments. This obviously represents a considerable improvement for such laboratories under threat of closure. Nevertheless, taking into account the time and cost associated with the whole process, one cannot help wondering whether it could not be done more simply given that the refusal of a purchasing authority or general practice fundholder to pay for such a request is inconceivable. In the case of the soft tissue tumour pathology service the charge would amount to about $£ 150$, excluding administrative costs. If the referring laboratories ended up paying several such referrals it could decimate their budget for consumables.

Finally, there are high volume and low cost services which are also best organised regionally. The clinical genetics service is a good example, for it is also changing dramatically with the emergence of new technologies for diagnosis and treatment. The introduction of a test such as the antenatal trivalent test for Down's syndrome presents the director of the service with the bewildering administrative tasks of persuasion and financial unbundling to obtain approval. Perhaps the review of the functions of regions recently announced by the secretary of state ${ }^{6}$ will recommend regions being responsible for pump priming or underwriting such developments as an expansion of their role of managing the purchasers.

It was hoped that the contracting process would be nonlegalistic, non-adversarial, and based on trust and mutual understanding. Instead it is turning out to be bureaucratic, shrouded in mystery, and potentially damaging. It seems ironic that central control has remained for supraregional services as for so much else in the NHS, yet regions have been encouraged to surrender to regional services.

More evidence may be needed of the difficulties faced by the directors of these services before remedial action is taken. Failing this, one can only imagine the awful possibility of the NHS having to face yet more claims for medical negligence arising from inappropriate care. It must be hoped that common sense will prevail and organisational arrangements will be put in place to ensure that our population is served properly.

\section{MALCOLM FORSYTHE}

Centre for Health Services Studies, Professor

University of Kent,

Canterbury CT2 7NF

1 Department of Health and Social Security. Health service development: supraregional services. London: DHSS, 1983. (HN(83)36.)

2 Department of Health. Supraregional services-additional guidance on criteria for designation. London DoH, 1988. (EL(88)P/153.)

3 Supra Regional Services Advisory Group, Department of Health. Annual report for the period ending 31 March 1992. London: SRSAG, 1992.

4 Donaldson LJ. Maintaining excellence: the preservation and development of specialised services. $B M$ 1 $^{2}$ 992;305:1280-3.

5 NHS Management Executive, Department of Health. Guidance on operation of notification arrangements for tertiary extracontractual neferrals. London: NHSME, 1992. (HSG(93)8.)

6 NHS Management Executive, Department of Health. The intermediate tier. London: NHSME, 1993. (EL(93)17.)

\title{
An old problem solved in child care
}

\section{The goal of a unified, combined child health service should be achieved}

The arrangements for child care in the NHS emerged largely by chance and have long been recognised to be illogical. In Britain general practitioners are increasingly involved in child health surveillance, traditionally the responsibility of clinical medical officers and senior clinical medical officers working in child health clinics. These doctors, some of whom work part time, will continue to provide secondary care in the community. A survey in 1992 found 1067 clinical medical officers, two thirds of whom were more than 10 years from retirement, and 643 senior clinical medical officers, half of whom had more than 10 years to serve. The future of these doctors and the service they have been providing has been considered by committee after committee, but the latest set of proposals ${ }^{1}$ seems likely to go through-if only because this government seems willing to take difficult decisions if they make economic sense.

The first real attempt to reform the anachronistic tripartite system of child care in Britain was the report in 1976 by Professor Donald Court, which received wide support from the medical profession but achieved little. ${ }^{2}$ In 1991 the British
Paediatric Association made a further attempt to grasp the nettle and defined the structure and functions of a combined child health service and its relation with the primary health care service for children. ${ }^{3}$ This report was welcomed by the secretary of state for health, and the specific problems of the career structure for doctors have now been tackled by a joint working party on medical services for children made up of representatives of the BMA and the Department of Health.

The main recommendations refer to the establishment of a consultant led combined child health service within the context of integration with the service provided by general practitioners. Consultant paediatricians (comunity child health) would be supported by two levels of career grade posts, probably staff grade and associate specialist. No new appointments would be made to the clinical or senior clinical medical officer grades. The requirements for postgraduate training and continuing medical education in both the hospital and community are defined clearly in the report. The resources currently available for medical staff working in child 
health will be maintained while the duties are restructured, and employing authorities are being asked to review their consultant requirements to achieve a consultant led service.

The increase in the numbers of consultants previously recommended by the British Paediatric Association ${ }^{4}$ is supported in the report; this will mean a further increase in training grades. In future, training in paediatrics at all levels will need to include work in hospitals and the community, and doctors in career grades, too, will increasingly work in both settings. Census data for 1990 and 1992 from the British Paediatric Association showed that there were too few paediatric medical staff with sufficient experience to provide emergency cover in many acute paediatric units. This problem could at least partly be relieved if full use was made of all the medical resources available, a point emphasised recently by the Audit Commission. ${ }^{5}$ One danger is that the community service could lose out to the acute workload of the hospital service, and this would need to be monitored by either the purchasing authority or the consultant paediatricians.

What will be the future for the clinical medical officer? They will be offered three choices: direct regrading, seeking a training post, or retaining their posts. Senior clinical medical officers may also apply for consultant posts. The report recommends a relaxation of the $10 \%$ restriction on staff grade numbers and a mechanism to allow appointment (in certain circumstances) to a consultant post without advertisement. It also envisages a long term need for non-consultant career grades, but when the consultant led combined child health service has been brought into full operation many of these posts may well be supplanted by training grades. Nevertheless a way will need to be found to provide continuity of care for the child and family in certain specialised aspects of the work.

The working party's proposals are of great importance to all doctors working in the child health service, and when implemented they will represent a major step towards achieving a combined child health service. The next hurdle is the problem inherent in services located in two or more separate trusts in hospitals and the community. Then, when a combined child health service has been achieved, the interface with primary care can be addressed-an issue already explored in a stimulating study by the consortium Caring for Children in the Health Services. ${ }^{6}$

KLDODD

Derbyshire Children's Hospital,

Consultant paediatrician

North Street,

Derby DE1 3BA

1 BMA and Department of Health. Report of the joint working party on medical services for children. London: BMA, 1992.

2 Committee on Child Health Services. Fit for the future. London: HMSO, 1976.

3 British Paediatric Association. Towards a combined child health service. London: BPA, 1991

4 British Paediatric Association. Paediatric medical staffing for the '90s. London: BPA, 1991.

5 Audit Commission for Local Authorities and the NHS in England and Wales. Children first-a study of hospital services. London: HMSO, 1993.

6 Thornes R. Bridging the gaps. London: Action for Sick Children, 1993.

\section{Dural puncture and headache}

\author{
Avoid the first but treat the second
}

Two papers in this week's journal highlight the morbidity that may result after accidental ( $\left.\mathrm{p} 883^{1}\right)$ or deliberate $\left(\mathrm{p} 917^{2}\right)$ dural puncture. The dura mater is a tough but leaky membrane supporting the more delicate but waterproof arachnoid mater. "Dural puncture" generally refers to puncture of both membranes. Puncture of the dura alone can go unrecognised and can cause problems unexpectedly when the arachnoid later tears. ${ }^{3}$

It is a popular misconception that rate of accidental puncture of the dura of around $1 \%$ is inevitable when less experienced anaesthetists attempt epidural insertion. Coupled with this is the erroneous belief that headache after dural puncture always gets better of its own accord. In this issue MacArthur and colleages report an incidence of accidental dural puncture in an obstetric unit of $1.6 \%$, the rate reportedly being inversely related to the anaesthetist's experience ( $p$ 883). ${ }^{1}$ Such rates have been condoned in standard texts from the same stable, ${ }^{4}$ and indeed a rate of $2 \cdot 6 \%$ has been reported for American residents in anaesthesia. ${ }^{5}$

Such rates, however, are not inevitable and are unacceptable. Indeed, in a recently published survey of the epidural records for 1969 to 1988 from the Birmingham Maternity Hospital the accidental dural puncture rate fell from greater than $7 \%$ initially to $0 \cdot 4-0.5 \%$ in the later years. ${ }^{6}$ Moreover, the rate was unrelated to the anaesthetist's grade. As Doughty pointed out, inadvertent dural puncture is avoidable and almost always due to human error. ${ }^{7}$ With careful teaching, new trainees attending a two week course under his supervision achieved an accidental dural puncture rate of $0.4 \%$ and, following his footsteps, others have achieved a rate of $0.3 \%{ }^{89}$
Though teaching and close supervision by an experienced and properly trained epiduralist contribute to these good results, another factor is the technique itself. The epidural space is generally detected by its low resistance to injection of fluid compared with that of the surrounding ligaments-the so called loss of resistance technique. Those who use an airfilled syringe to detect loss of resistance regard a dural puncture rate of $1-2 \%$ in training as inevitable, whereas those who use a saline filled syringe achieve better results. ${ }^{89}$ This is confirmed in the Birmingham survey. ${ }^{16}$

Proponents of the air technique say that detecting dural puncture is easier because cerebrospinal fluid dripping from the needle cannot be mistaken for saline just injected. But it is more important to use a technique that will minimise the occurrence of dural puncture than one that will facilitate diagnosis. In practice the diagnosis is no more difficult with saline than with air. ${ }^{10}$ Moreover, using air has other undesirable side effects ${ }^{9}$ and should therefore be eschewed.

Accidental dural puncture deserves attention because its sequelae can be serious. Headache may, however, occur after any dural puncture and results from low intracranial pressure after leakage of cerebrospinal fluid-the larger the needle the more frequent and severe the headache. ${ }^{11}$ Headache is reduced when the split made by the needle bevel is parallel to the longitudinal dural fibres. ${ }^{5}$ Immediate, but usually temporary, relief follows the injection of a large volume of fluid into the lumbar epidural space, displacing cerebrospinal fluid from the spine to the cranium.

Young people and women are more susceptible to headache after dural puncture than others, with obstetric patients the 